\section{Commentary: Colorectal pulmonary metastasectomy- which way to lean: Right, left, or somewhere in between?}

\author{
Robert B. Cameron, MD
}

For decades, patients with limited colorectal pulmonary metastases, who account for $5 \%$ to $15 \%$ of all patients with colorectal cancer, have undergone metastasectomy in the belief that such patients likely will live longer and may even be cured of their disease. ${ }^{1}$ Case series suggest that this is true; however, prospective, randomized controlled trials confirming this belief and defining the most appropriate patient characteristics are lacking, including the recent international Pulmonary Metastasectomy versus Continued Active Monitoring in Colorectal Cancer trial, which failed to accrue patients adequately. ${ }^{2}$ In the meantime, tremendous effort has been directed at defining prognostic factors that may be used to select favorable patients for surgery. A review of recent relevant studies was reported by Zellweger and colleagues. ${ }^{1}$ Factors, such as a rectal versus colon primary site, and in some studies, age ( $>70$ years), sex (men), disease-free interval ( $<24$ months), number of metastases $(\geq 3)$, regional lymph node involvement $(+)$, preoperative carcinoembryonic antigen levels (elevated), and mutation status (eg, KRAS, BRAF, HER2, and microsatellite instability) have been noted to convey a poor prognosis. ${ }^{1,3}$

In a retrospective review, Corsini and colleagues ${ }^{4}$ added a novel prognostic factor to the long list of existing purported prognostic factors; that is, primary colon cancer location.

From the Division of Thoracic Surgery, Department of Surgery, David Geffen School of Medicine at UCLA, Los Angeles, Calif, and Division of Thoracic Surgery, Department of Surgery and Perioperative Care, West Los Angeles VA Medical Center, Los Angeles, Calif.

Disclosures: The author reported no conflicts of interest.

The Journal policy requires editors and reviewers to disclose conflicts of interest and to decline handling or reviewing manuscripts for which they may have a conflict of interest. The editors and reviewers of this article have no conflicts of interest.

Received for publication April 14, 2020; accepted for publication April 15, 2020; available ahead of print May 4, 2020.

Address for reprints: Robert B. Cameron, MD, Division of Thoracic Surgery, Department of Surgery, David Geffen School of Medicine, 10780 Santa Monica Blvd, Suite 100, Los Angeles, CA 90025 (E-mail: rcameron@mednet.ucla.edu).

J Thorac Cardiovasc Surg 2021;162:306-7

$0022-5223 / \$ 36.00$

Copyright (c) 2020 by The American Association for Thoracic Surgery

https://doi.org/10.1016/j.jtcvs.2020.04.073

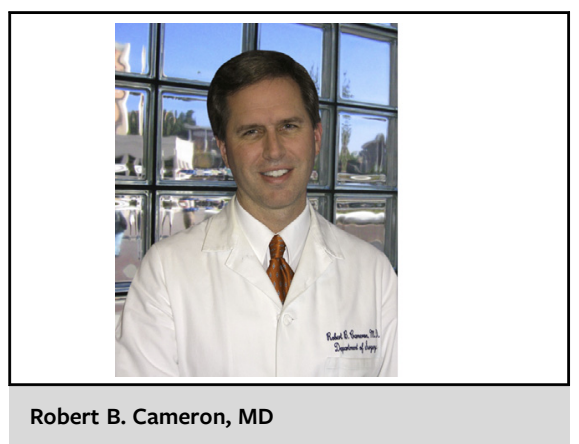

CENTRAL MESSAGE

Right-sided colorectal primary tumors carry a worse prognosis than left-sided tumors, but the ultimate decision to perform pulmonary metastasectomy should be based on estimated surgical benefit.

From 2011 to 2017, 194 patients underwent pulmonary metastasectomy for a median of 3 nodules measuring a median of $1.4 \mathrm{~cm}$. Surprisingly, even in this contemporary period, most patients underwent open procedures via thoracotomy $(114 ; 59 \%)$ or median sternotomy $(8 ; 4 \%)$. Right-sided colon primary tumor location was associated with negative prognostic implications compared with left-sided colon primary locations (hazard ratio, 0.31; $P=.036$ ), with a Kaplan-Meier median survival of 90 months for left-sided/rectal primary tumors (95\% confidence interval, 82-not reached) compared with 55 months (95\% confidence interval, 49-not reached) for right-sided tumors.

With this additional prognostic data, surgeons may be tempted to primarily target good prognostic patients for surgical resection, such as female patients younger than age 70 years, with left-sided cancers, a $>24$-month diseasefree interval, $<3$ metastases, no associated lymph node spread, no mutations, and a normal carcinoembryonic antigen level. Indeed, this strategy will produce outstanding surgical results simply by selecting patients with the best prognosis; yet, a favorable prognosis does not necessarily equate to surgical benefit. For instance, lung cancer patients with N1 nodal disease have a significantly worse prognosis 
than N0 patients but both derive substantial benefit from surgical resection. It is enormously important not to overemphasize the utility of prognostic factors. Although prognosis is important for comparisons between groups and/or studies, it also is a form of selection bias. Simply selecting the best prognostic patients does not guarantee surgical benefit.

Undoubtedly, prognostic factors are valuable when considering metastasectomy in colorectal cancer patients. It also is clear that surgical benefit may be derived in both good and poor prognostic groups. That is why prospective randomized clinical trials remain critical in determining true surgical benefit in any clinical/surgical situation rather than accepting the mere appearance of good outcomes based on the selection bias inherent in the sole use of prognostic factors in patient selection.

\section{References}

1. Zellweger M, Abdelnour-Berchtold E, Krueger T, Ris HB, Perentes JY Gonzalez M. Surgical treatment of pulmonary metastasis in colorectal cancer patients: current practice and results. Crit Rev Oncol Hematol. 2018;127:105-16.

2. Treasure T, Farewell V, Macbeth F, Monson K, Williams NR, Brew-Graves C, et al Pulmonary metastasectomy versus continued active monitoring in colorectal cancer (PulMiCC): a multicenter randomized clinical trial. Trials. 2019;20:718-31.

3. Afrăsânie VA, Marinca MV, Alexa-Stratulat T, Gafton B, Păduraru M, Adavidoaiei AM, et al. KRAS, NRAS, BRAF, HER2 and microsatellite instability in metastatic colorectal cancer- practical implications for the clinician. Radiol Oncol. 2019:53:265-74.

4. Corsini EM, Mitchell KG, Correa A, Morris VK, Antonoff MB. Effect of primary colorectal cancer tumor location on survival after pulmonary metastasectomy. J Thorac Cardiovasc Surg. 2021;162:296-305.
See Article page 296.

\section{Commentary: Molecular biology, location, and survival following pulmonary metastasectomy for colorectal carcinoma}

\author{
Anna L. McGuire, MD, MSc, FRCSC
}

In this issue of the Journal, Corsini and colleagues ${ }^{1}$ explore a truly novel concept in thoracic surgery relating to pulmonary metastasectomy for primary colorectal carcinoma: the independent impact of bowel segment location on patient survival time. Herein we are provided

\footnotetext{
From the Division of Thoracic Surgery, Department of Surgery, Vancouver General Hospital, University of British Columbia; and Vancouver Coastal Health Research Institute, Vancouver General Hospital, Vancouver, British Columbia, Canada.

Disclosures: Dr McGuire receives in-kind research support from Contextual Genomics, Inc (Vancouver, British Columbia, Canada), and research funding from AstraZeneca Canada for study unrelated to the current submission.

The Journal policy requires editors and reviewers to disclose conflicts of interest and to decline handling or reviewing manuscripts for which they may have a conflict of interest. The editors and reviewers of this article have no conflicts of interest.

Received for publication April 19, 2020; accepted for publication April 20, 2020; available ahead of print May 1, 2020.

Address for reprints: Anna L. McGuire, MD, MSc, FRCSC, Division of Thoracic Surgery, Department of Surgery, Vancouver General Hospital, Vancouver Coastal Health, 2775 Laurel St, Suite 7113, V5Z 1M9, Vancouver, British Columbia, Canada (E-mail: anna.mcguire@vch.ca).

J Thorac Cardiovasc Surg 2021;162:307-8 $0022-5223 / \$ 36.00$

Copyright (c) 2020 Published by Elsevier Inc. on behalf of The American Association for Thoracic Surgery

https://doi.org/10.1016/j.jtcvs.2020.04.075
}



a tool that, with ongoing study, could further refine existing prognostic models following pulmonary resection., ${ }^{2,3}$ Particularly relevant in the current evolving era of molecular diagnostics and precision oncology, there is value in synthesizing these data with a purpose to clinically inform risk/benefit discussions with patients regarding multimodal treatment decisions. As thoracic surgical oncologists, we aim to maximize survival as well as quality of life for each patient with pulmonary metastases. We understand that pulmonary metastasectomy is only one 